\title{
A mitologia da intolerância norte-americana a partir da perspectiva de D.W.Griffith
}

\section{LILIAN CREPALDI DE OLIVEIRA}

Resumo

$\mathrm{O}$ artigo tem como objetivo principal verificar como elementos de intolerância aparecem na narrativa do filme O Nascimento de Uma Nação, dirigido por D.W. Griffith. Por meio da análise fílmica, buscamos também avaliar como o cinema constrói e reproduz preconceitos numa dada sociedade. Numa perspectiva mais abrangente, buscase compreender o surgimento de movimentos racistas e intolerantes nos séculos XIX e XX.

Palavras-chave:

Intolerância, mitos, filme $O$ nascimento de uma nação 


\section{The mythology of American intolerance from the perspective of D.W.Griffith}

\section{LILIAN CREPALDI DE OLIVEIRA}

\section{Abstract}

The article's main objective is to verify how elements of intolerance appear in the narrative of the movie The Birth of a Nation, directed by D.W. Griffith. Through film analysis, we also aim to assess how the movie fabricates and reproduces prejudices in a given society. In a larger perspective, we seek to understand the emergence of intolerant and racist movements in the nineteenth and twentieth centuries. 


\section{Introdução}

O cinema, assim como as obras literárias, não tem ligação formal com os acontecimentos históricos e nem deve fidelidade aos mesmos. Dessa forma, tanto o historiador como o público que assiste à obra deve pesar o que é recurso estilístico e o que é fato histórico. Assim, o problema de nossa análise surgiu da necessidade de conhecer como a sociedade americana é representada no filme O Nascimento de Uma Nação. Para tanto, nos perguntamos: Como a intolerância, em sua vertente racista, é mostrada no filme?

Pela duração do filme, optamos por uma análise geral em detrimento da análise cena por cena. Desta forma, acreditamos que é mais produtivo analisar, segundo conceitos como mito, nação, intolerância e racismo, o conjunto de ações ao longo da narrativa e o desenvolvimento das personagens.

Na primeira parte desse trabalho, discorremos brevemente sobre a importância do cinema e da narrativa como objeto de estudo. Num segundo momento, realizamos uma síntese da história contemporânea norte-americana. Por fim, analisamos o filme segundo os conceitos descritos acima. Dessa forma, delimita-se como objetivo secundário do artigo discorrer sobre como a linguagem fílmica apresenta ao espectador os atores e as movimentações sociais do período da Guerra Civil Americana.

\section{Cinema e narrativa}

Para Ferro, "a linguagem do cinema revela-se ininteligível e, como a dos sonhos, é de interpretação incerta" (1992, p.79). Passível de inúmeras críticas, assim como qualquer outra fonte, a narrativa cinematográfica, e suas articulações com tem- 
po/espaço, tem sido estudada não somente por historiadores, como também por psicanalistas e estudiosos de ciências humanas. Dessa forma, o cinema como forma de expressão cultural é, sinteticamente, entendido como um meio de autorepresentação da sociedade.

De acordo com Ferro (1992), qualquer imagem tem possibilidade de leitura e contra-leitura. Assim, o cinema como documento deve ser analisado de acordo com a intencionalidade do diretor/produtor e segundo o tempo histórico entre o emissor e o receptor. Ou seja: avaliar as concepções de mundo de quem produz e de quem assiste é tarefa primordial para se compreender a narrativa, tendo em mente que o filme não está separado dos elementos sociais e que, no cinema, a imagem ganha dimensão de vida real. Vale lembrar que o cinema está diretamente relacionado ao conceito de narrativa. Para Walter Benjamin:

O saber, que vinha de longe - do longe espacial das terras estranhas, ou do longe temporal contido na tradição -, dispunha de uma autoridade que era válida mesmo que não fosse controlável pela experiência. Mas a informação, ela precisa ser compreensível "em si e para si". Muitas vezes não é mais exata que os relatos antigos. Porém, enquanto esses relatos recorriam freqüentemente ao miraculoso, é indispensável que a informação seja plausível. Nisso ela é incompatível com o espírito da narrativa. Se a arte da narrativa é hoje rara, a difusão da informação é decisivamente responsável por esse declínio.

Cada manhã recebemos notícias de todo o mundo. E, no entanto, somos pobres em histórias surpreendentes. A razão é que os fatos já nos chegam acompanhados de explicações. Em outras palavras: quase nada do que acontece está a serviço da narrativa, e quase tudo está a serviço da informação. Metade da arte narrativa está em evitar explicações. (...) Ele (o leitor) é livre para interpretar a história como quiser, e com isso o episódio narrado atinge uma amplitude que não existe na informação. (BENJAMIN, 1987, p.202)

Assim, narrar não é apenas informar. A narrativa oral, assim como a narrativa escrita e o poema, trabalha a palavra, valorizando seu aspecto polissêmico e dando abertura para uma leitura mais profunda e complexa. Apesar da linguagem cinematográfica não ser essencialmente narração, ela surpreende e inova quando deixa o leitor/espectador livre para interpretar 
os fatos. Num filme mudo, a montagem do diretor substitui a palavra pelo encadeamento lógico das cenas e outros recursos.

\section{A “invenção” da nação norte-americana}

A historiografia acerca da história norte-americana, especialmente sobre a Guerra Civil (1861-1865), é extremamente vasta e possui diversas abordagens e metodologias. Contudo, várias pesquisas carecem de rigor científico e acabam romanceando fatos históricos em nome de dada ideologia. Dessa forma, para realizarmos uma pequena síntese acerca da história da guerra civil americana, de forma didática e objetiva, optamos por utilizar uma obra nacional, intitulada Estados Unidos: a consolidação da nação, da historiadora Mary A. Junqueira (2001).

Muito além de um compêndio de informações acerca da História Norte-Americana, o objetivo principal da autora é discutir o excepcionalismo norte-americano, que pode ser visto não somente nos discursos políticos, como também nas relações sociais. Dessa maneira, Mary A. Junqueira (2001) reforça a ideia da (re)construção da História Americana nas escolas públicas e de sua chegada até nós por intermédio da cultura média americana, que tem em Hollywood sua maior expressão.

Já na introdução da obra, a autora discute como se dá a construção da identidade nacional, ressaltando a importância dos manuais escolares no reforço das crenças e na sua perpetuação ao longo das gerações. É por meio deste eficiente projeto pedagógico que os americanos crescem sob a égide de viverem na nação escolhida e de ser o povo escolhido (questão do excepcionalismo).

É também nos manuais que se definem quem são os heróis e os bandidos, o que reforça o caráter maniqueísta do imaginário norte-americano. A ênfase dos discursos dos livros na velha tríade - primeira República, mais velha democracia e mais antiga constituição - incutem nos cidadãos um certo sentimento de superioridade, que será, cada vez mais, reforçado ao longo dos anos, sobretudo com o Destino Manifesto, espécie de projeto pedagógico baseado no ideal civilizatório das Luzes que coloca os americanos como o povo eleito.

Assim, sendo um povo "superior" aos demais, os Estados Unidos teriam, a partir da Independência (1776), formado um país e uma cultura hegemônica. A própria historiografia americana reforça esta ideia dos Estados Unidos como pre- 
cursores da modernidade e irradiadores de tecnologia e cultura. Nesse contexto, surge ainda no século XIX a ideia dos Estados Unidos como um mito fadado ao sucesso.

Junqueira (2001) também discute como se dá a criação e o reforço dos mitos fundadores da nação americana, tão citados em discursos de chefes de nação, líderes carismáticos e pela cultura média do país, que veem nestes heróis verdadeiros pais da nação. A ideia dos peregrinos e da pureza dos colonos que fugiram de perseguições religiosas na metrópole inglesa reforça este caráter heróico dos pais fundadores que, segundo a autora, são um dos principais responsáveis pelo mito de superioridade e dos EUA como a terra da grande promessa.

Para mostrar como esta ideia de pais fundadores da nação surgiu, a autora remonta ao período posterior ao processo de Independência norte-americano, quando a questão de como fazer a união das colônias foi debatida. Num primeiro momento, Confederação, houve uma total desunião. Em seguida, com a Convenção, passou-se a discutir os meios para se chegar a uma possível união. Num terceiro momento, quando federalistas (que propunham um governo central) e anti-federalistas (que propunham autonomia dos poderes locais) discutem qual seria a forma de governo ideal, os federalistas conseguem que a Constituição seja ratificada e surge a Federação.

Nesse período, surge também a figura do Mister President e do processo eleitoral norte-americano. Devido às inúmeras diversidades das colônias, surgiu a necessidade da criação de mitos e símbolos que fossem comuns a toda nação. Dessa maneira, os heróis foram escolhidos entre os personagens que participaram da Independência norte-americana já que, assim como os peregrinos que fugiram da Inglaterra, era necessário um elemento identificador comum à nova nação. $\mathrm{O}$ processo de exclusão começa neste momento em que os peregrinos seriam os escolhidos de Deus e buscariam a construção de uma República Clássica na América. Esta imagem de superioridade está presente até os dias de hoje, em que cada vez mais é reforçada pela perpetuação da cultura pop americana. Vale mencionar como se deu o processo de escolha destes pais fundadores: como seria possível representar todos os americanos se somente os peregrinos eram glorificados? Escolhendo heróis nascidos no sul e fazendo com que, desta forma, a noção de povo eleito se estendesse aos demais norte-americanos.

Além da questão dos mitos norte-americanos, Junqueira (2001) também aborda temas como a formação da nação, a guerra civil, a questão indígena e negra, o advento da moder- 
nidade e a Doutrina Monroe, sempre fazendo relações com a construção do imaginário mítico. Para explicar a formação do país, a autora ressalta o clima ideológico da necessidade de expansão. Como a colonização se deu na parte litorânea dos Estados Unidos, o resto do território vai sendo incorporado ao longo do tempo. Como exemplos de expansão, podemos citar o caso dos Apalaches, quando começa o massacre dos indígenas. Também a conquista do Oeste, visto como lugar de pureza e regeneração pelos transcendentalistas, foi um importante episódio na história norte-americana como reforçador de mitos como cowboys e da famosa dualidade americana de winner versus looser (vencedor versus perdedor).

Especificamente sobre a guerra civil entre o norte da elite burguesa e o sul das grandes propriedades e do escravismo, a autora coloca a questão das tarifas de importação como mola propulsora da guerra. Enquanto o Norte desejava que as tarifas fossem altas para estimular o desenvolvimento da produção interna, o sul desejava que fossem baixam para não prejudicar as exportações. Assim, a guerra aparece como motor para o progresso e necessária para acabar com o sul retrógrado. Com o fim da guerra e a vitória do norte, a questão dos negros vem à tona e surgem organizações racistas, como a K.K.K, com o intuito de purificar a nação e combater os indesejáveis e selvagens negros, conforme o discursos majoritário sulista:

Muitos brancos reagiram com violência contra os negros que procuravam viver e garantir sua liberdade. Especialmente nas regiões em que a presença das autoridades federais não era tão forte, as chacinas de adultos e crianças, os espancamentos, os enforcamentos coletivos de negros e a destruição de suas casas e bens por brancos armados eram bastante comuns. Muitas vezes as justificativas apresentadas na época para essas e outras manifestações de ódio racial não passavam de indignação: 'sentiam-se ofendidos com o atrevimento dos negros', que não os tratavam com a mesma 'deferência' e submissão dos tempos da escravidão (JUNQUEIRA, 2001, p.91).

Também o fim da guerra foi o espelho para mostrar o desenvolvimento técnico dos norte-americanos com a questão dos armamentos, o que depois culminará num desenvolvimento em diversos campos. Nesse sentido, a visão de progresso é simbolizada com a construção das ferrovias e com o arranque do desenvolvimento industrial a partir dos monopólios, proporcionado pela capacidade empreendedora do 
self-made man, outra construção mítica norte-americana. Por fim, a autora aborda a Doutrina Monroe e a visão intervencionista sobre as outras nações do mundo. Como o povo "eleito", é missão dos norte-americanos prezar pelo desenvolvimento do resto do mundo.

As construções míticas norte-americanas perpassam todo o discurso de Junqueira (2001) para explicar como se deu a construção da nação. A crença de povo eleito e de superioridade moveu a sociedade americana na busca de união interna e desenvolvimento. Até hoje, a visão maniqueísta do mocinho e do bandido está presente no cotidiano dos norte-americanos, provando a tese de que o mito se cria e se reforça no fazer da História. "Muitos dos mitos forjados no século XIX permanecem por muito tempo como uma espécie de 'bem simbólico' da nação e podem ser utilizados para defender ou justificar esta ou aquela posição" (JUNQUEIRA, 2001, p.124). Vale ressaltar que Hollywood é o espaço favorito para a construção mítica dessa história norte-americana em nome das ideologias.

\section{O filme O Nascimento de uma nação e a intolerância}

O filme dirigido por David Wark Griffith (XAVIER, 1984), considerado um dos precursores do cinema clássico, é de 1915 e possui 187 minutos. Mudo e com legendas em inglês, $O$ Nascimento de Uma Nação é a primeira narrativa cinematográfica a mostrar técnicas inovadoras de filmagem e montagem, como locações abertas, movimentos diversos de câmera, plano americano (para diferenciar da interpretação teatral), campo/ contra-campo e o "enquanto isso" (ações paralelas), entre várias outras. Essa estrutura inaugurada por Griffith é utilizada até hoje em grande escala pelos cineastas ao redor do mundo.

Em linhas gerais, o filme O Nascimento da Nação pode ser classificado como um épico, tendo em vista que sua estrutura narrativa é linear e se baseia não somente em trajetórias de vida, como também em versões da história americana. Podemos até mesmo dizer que a narrativa é uma versão audiovisual do Destino Manifesto, já exposto anteriormente.

Baseado na obra literária The Clansman, de Thomas Dixon, a narrativa cinematográfica se inicia com a apresentação das duas famílias centrais da trama: uma do norte e uma do sul, esta última ligada à tradição agrária.

Logo no início, é possível perceber as construções ideológicas do diretor, que nos estimula a simpatizar mais com a 
família sulista, não somente pela maior humanidade e solidariedade entre os membros da família, como também pela pureza das mocinhas brancas. Griffith descreve o Sul como uma terra perfeita, que "não podia ficar melhor". Com o advento da guerra, o drama particular da família sulista tornar-se-á um drama coletivo.

Ao longo de toda a narrativa, mostra-se o cotidiano e as adversidades da vida dos Stoneman (família do norte abolicionista, industrial e liberal) e, sobretudo, dos Cameron (família do sul escravista e conservador). Nesse contexto, a guerra é o elemento transformador não somente das relações sociais, como também das ações políticas de ambas as famílias. Diversos elementos das relações cotidianas também são apresentados ao espectador, como a ligação entre pais e filhos, os cuidados com as crianças e com a terra e a aparente indiferença para com os criados negros. Ambas as famílias gozam de prosperidade e respeitabilidade junto à comunidade local até que a guerra civil trará desorganização e caos.

Após a apresentação dos núcleos da trama, os antigos amigos Phil Stoneman, filho de um político do norte, e o mocinho Benjamin Cameron, oriundo de uma tradicional família sulista e apelidado de Pequeno Coronel, se enfrentam numa batalha da Guerra Civil. As cenas de conflito armado são filmadas em plano aberto, uma novidade na época, e a música orquestrada transmite uma forte carga de emoção.

Benjamin é ferido durante o combate e seu amigo Phil o leva a um hospital em Washington, onde ele conhecerá a irmã de Phil, Elsie, e se apaixonará. As cenas delicadas de Elsie tomando conta do ferido têm como objetivo despertar-nos grande simpatia pelo casal branco.

Ao se recuperar e ser anistiado pelo próprio presidente Abraham Lincoln, Ben volta ao sul para reencontrar a família e descobre que todo o patrimônio havia sido vendido em nome da causa da guerra. Somando-se a isso, os escravos haviam sido libertados e ganharam direito de voto. A cena em que Ben retorna a Piedmont e se vê frente à destruição dos bens da família é bastante emotiva, não somente em vista da música dramática, como também pelos planos de câmera mostrando sua tensa expressão facial.

É interessante notar que, para conferir legitimidade aos acontecimentos mostrados na tela, o diretor utiliza documentos oficiais e periódicos da época. Não basta uma construção narrativa puramente autoral: é preciso reforçá-la com documentos do período para que o público entenda que é a 
verdade que está sendo contada. A reconstituição do assassinato de Lincoln, por exemplo, é bastante verossímil e utiliza vasta documentação.

Com o fim da guerra civil (1865), a vitória do Norte e a liberdade dos escravos, as ações mudam em ambos os lados - brancos e negros - na narrativa cinematográfica. Após uma eleição fraudenta, os negros dominam a Câmara e aprovam leis que, dentre outras coisas, permitem o casamento interracial. Diante de tamanhas arbitrariedades, o mocinho Ben decide fundar uma organização para salvar os costumes do sul e evitar os abusos dos negros, a Ku Klux Klan. Vale lembrar que as motivações para a fundação da KKK vão além da defesa do bem coletivo e adentram a esfera particular, tendo em vista que o Vice-Governador, o mulato Silas Lynch, também gosta de Elsie.

Fundada em 1868, a KKK buscava garantir socorro aos sulistas derrotados e opunha-se à igualdade social e política dos negros. A organização definia-se como:

[...] uma instituição de Cavalheirismo, Humanidade, Misericórdia e Patriotismo; [...] cujos objetivos peculiares são [...] proteger os fracos, inocentes e indefesos contra as indignidades, injustiças e ultrajes dos sem-lei - violentos e brutais -, acudir os injuriados e oprimidos, socorrer os sofredores e infelizes e, sobretudo, as viúvas e órfãos de soldados confederados (JUNQUEIRA, 2001, P.90).

Griffith descreve a Klan como "a organização que salvou o Sul da anarquia negra”. É preciso lembrar que, na tentativa de mostrar o quanto os negros eram felizes na condição de escravos, Griffith mostra-os dançando e com expressões felizes, enquanto os brancos proprietários observam admirados. Contudo, não podemos esquecer que o sistema escravista foi uma forma brutal de coerção dos escravos às imposições dos senhores, em nome do bem-estar financeiro e econômico da nação. Para tanto, os escravocratas sulistas não mediram esforços, usando violência e racismo como meios para provar a dita superioridade, justificando, assim, a condição de submissão e agressão vivida pelos descendentes de africanos.

Nesse contexto de aparente liberdade dos negros, a $\mathrm{Ku}$ Klux Kan surge como uma espécie de fatalidade, uma engenhosidade dos indivíduos brancos sulistas para salvar a moral e os bons costumes da corrupção negra que invadira o país. Dessa forma, a KKK visa, inicialmente, amedrontar os "bárbaros" 
que prejudicavam o status quo e se mostra bastante inofensiva e, até mesmo, benéfica para o momento atual. Contudo, a ação da KKK visa o estabelecimento de uma nação W.A.S.P. (White Angle-Saxon Protestant). Nesse contexto, a nação é reinventada a partir de um mito fundador e este mito torna-se ideologia. O mito fundador é a saída dos pais fundadores da Europa e sua ida aos Estados Unidos, uma espécie de Terra Prometida, o lugar da liberdade e do livre professar da religião.

Numa perspectiva crítica dos pais fundadores, o historiador John Hope Franklin, num ensaio intitulado O legado dos Pais fundadores, afirma que "a segregação, a discriminação e a degradação raciais de modo algum são acidentes inesperados na história desta nação. Provêm direta e logicamente do legado que os pais fundadores outorgaram aos Estados Unidos contemporâneos" (1999, p.197).

Anderson define nação como "uma comunidade política imaginada - e imaginada como implicitamente limitada e soberana" (1989, p.14). A nação estaria relacionada ao elo identitário e, sendo inventada, é passível de apropriações ideológicas. Ao estudar a diversidade cultural na Indonésia, Anderson conclui que a nação é o imaginário que se constrói a partir das elites, que se valem do poder e da exploração para "criar" um projeto de nação. Contudo, vale ressaltar que as dimensões identitárias são históricas e se reconstroem não somente a partir das elites, como também utilizando elementos da chamada cultura popular.

Assim, as cenas que mostram as mulheres sulistas produzindo uniformes e alimentando os membros da KKK constituem-se numa tentativa do diretor não somente de conferir legitimidade ao movimento insurgente, como também de mostrar a reinvenção mítica da nação a partir da força e persistência branca.

A partir da afirmação "a história está na mitologia e a mitologia está na história” (1996, p.48), Franco Júnior desenvolve sua ideia de que o mito é retomado e, por sua vez, recriado de acordo com as necessidades do tempo vivido, ou seja, mitos em repouso por alguns anos podem vir à tona na tentativa de explicar certos acontecimentos. Pela existência de distintas culturas, a nova criação mítica terá significados também distintos. Tal processo de recuperação e recriação mítica dar-se-ia através do fenômeno da transculturação, ou seja, uma relação mais dialética entre as diferentes culturas, onde os distintos tempos se cruzariam por meio da utilização de elementos comuns (como os mitos). Assim, reconhece-se 
a utilização mítica anterior, mas recria-se de acordo com o novo contexto vivido. Os integrantes da KKK, neste contexto, recriam a noção de pais fundadores na nação para pregar a supremacia branca.

Para Franco Júnior (1996, p.48) “mito não é a história dos eventos políticos ou econômicos, mas história da sensibilidade coletiva”. É por meio dos rituais que o mito torna-se presente, apesar do mesmo estar inserido num contexto a-histórico por ser recriado ao longo dos tempos. Segundo Eliade (1998, p.316) "um ritual não se limita a repetir o ritual precedente- que é, ele próprio, a repetição de um arquétipo: ele é contíguo e continua-o, periodicamente ou não". Assim, o mito "é expressão de longa duração, expressão de valores fortemente enraizados, daí a larga permanência de um relato mítico. Permanência, contudo, sujeita a flutuações decorrentes das condições históricas permanentes" (FRANCO JUNIOR, 1996, p.47).

Frequentemente, o tempo atual dá espaço ao tempo do sagrado já que temos a necessidade constante de resgatar alguns mitos na tentativa de explicar os fenômenos do hoje. "Encontramos, pois, no homem, a todos os níveis, o mesmo desejo de abolir o tempo profano e de viver no tempo sagrado" (ELIADE, 1998, p.331). Ou seja: a insatisfação com os acontecimentos do presente faz com que o homem sonhe em viver num tempo que nem ele mesmo sabe que existiu. Não se busca explicações no mundo terreno, busca-se um tempo mítico que possa aliviar os sofrimentos atuais. Busca-se, enfim, um tempo que acalmaria o presente. Na narrativa de Griffith, esta é a função da Klan.

Dessa forma, a narrativa de O Nascimento de Uma Nação tem como função mítica mostrar o conflito entre negros e brancos e a consequente superioridade dos últimos, sendo os brancos os legítimos vitoriosos da nação por conseguirem tirar os negros do poder e restabelecer a paz.

A desmoralização dos negros já ocorrera durante toda a narrativa e fora ressaltada quando uma das filhas dos Cameron saltara de um penhasco para não ser estuprada ou quando os negros, com poder recém-adquirido, fazem bagunça numa sessão parlamentar. Atos como se embebedar durante as sessões ou colocar os pés descalços sobre as bancadas são mostrados como selvageria na narrativa, contradizendo a estabilidade branca. Contudo, vale ressaltar que as conquistas dos negros com o fim da Guerra Civil tiveram duração breve e o conservadorismo se manteve nos estados do sul. Os grandes 
proprietários de terras se reergueram e mantiveram-se no poder político, inclusive tendo voz ativa na elaboração de códigos de leis intolerantes que pregavam a segregação racial, intensamente presentes nos Estados Unidos até a década de 1960.

Para essa pretensa recriação da nação, também são interessantes as cenas que mostram a crise econômica do sul durante a guerra, com os negros desestabilizando estruturas e provocando o caos, ao passo que as mulheres brancas fazem resistência. Durante a crise, nota-se, novamente, a intenção do diretor para que simpatizemos com a família sulista, tida como um pilar de humanidade e força.

Uma das cenas mais interessantes para a análise é a perseguição sofrida pela mocinha sulista. Tecnicamente, a cena apresenta diversos elementos inovadores que são utilizados até hoje pelos cineastas, como closes nos rostos raivosos dos negros, sequências rápidas dos cavalos galopando, movimentos de câmera arrojados, takes abertos para mostrar as especificidades da locação, entre tantas outras. Contudo, ideologicamente, a cena reforça a imagem da branca pura e imaculada tentando se defender do negro corrompido. Obviamente, o desfecho é o único possível para a construção racista de Griffith: os mocinhos brancos salvam a mocinha casta de ser estuprada pelos bandidos negros.

Este viés negativo em relação ao negro é latente na figura do vice-governador, o maior vilão da narrativa, que, além de maltratar animais indefesos, diz a doce Elsie que construirá um Império Negro e que ela estará a seu lado. Somando-se a isso, a aparente simpatia dos Stoneman para com os negros se daria, segundo o diretor, porque Austin Stoneman tinha um caso com sua subalterna mulata. Assim, pode-se inferir que o racismo se impõe nas relações interpessoais próximas, na violência moral cotidiana e na crença numa superioridade em relação ao outro. Para Bauman:

o racismo destaca-se por um costume de que é parte integrante e que racionaliza: costume que combina estratégias de arquitetura e jardinagem com a da medicina a serviço da construção de uma ordem social artificial, pelo corte de elementos da realidade presente que nem se adequam à realidade perfeita visada nem podem ser mudados para se adequarem (1998, p.87).

Durante o filme, os negros, que são atores brancos maquiados, são mostrados como ignorantes, violentos e manipuláveis. São, de maneira simplista, objetos da história. Em 
contrapartida, os brancos representam poder, conhecimento e são imbuídos dos mais louváveis valores. Homens da ação, e da reconstrução após a guerra, são os sujeitos da narrativa. $\mathrm{O}$ padrão de ideologia que nos é colocado é o drama dos brancos frente à guerra e, sobretudo, ao negro selvagem e mau caráter. Inventa-se uma tradição: a dos homens brancos descendentes dos pais peregrinos a serviço da ideologia racista.

O final da narrativa segue o intuito racista da construção de Griffith: os heróis brancos e puros da KKK salvam a já tão sofrida família sulista do ataque de um exército negro. Em linhas gerais, a construção de Griffith tem como objetivos glorificar o racismo e pregar a dominação branca, fazendo com o espectador torça por um final feliz do mocinho, que funda a Ku Klux Klan para salvar o sul da corrupção moral dos negros.

Vale dizer que o filme foi o primeiro a ultrapassar os US\$ 10 milhões de bilheteria e a ser exibido na Casa Branca. Apesar de sua proibição em alguns estados e o boicote por diversas empresas, muitos afirmam que sua exibição nos Estados Unidos foi responsável pelo recrudescimento de movimentos racistas como a KKK, demonstrando que a intolerância torna-se perigosa quando se transmuta em prática social.

Para Umberto Eco, o caminho para a diminuição de fenômenos ligados à intolerância é compreender a raiz das práticas culturais, buscando a origem da chamada intolerância selvagem. "Este é o nosso desafio. Saber regredir até o fundo obscuro da intolerância selvagem. Cavar, cavar até encontrála, bem lá onde ela se forma, antes que se torne objeto de tratados eruditos" (2000, p.19).

Já para Ricceur, o importante não é a intolerância em si, mas sim quando os indivíduos realizam práticas sociais "legitimadas" nas diferenças (quase sempre "superioridade") em relação ao outro. Desta forma, o pensamento intolerante torna-se prejudicial quando se transforma em ação. Para o autor, "o que está em jogo é nada menos que a relação a ser estabelecida entre o universal e o histórico, na luta contra a intolerância" (2000, p.20).

\section{Considerações finais}

Explicar a manifestação de pensamentos tão radicais como a intolerância ou o racismo é tarefa extremamente difícil até para os mais renomados estudiosos da área. Muitas ideias simplistas foram aceitas durante anos, não somente na comunidade científica como também na sociedade civil. Pen- 
samentos romanceados hoje são bastante combatidos por serem imbuídos de anacronismos e carecerem de veracidade histórica. Também a grande paixão pelo tema do racismo fez com que se produzissem mais romances e filmes que trabalhos científicos dignos de credibilidade.

Atualmente, sabe-se que a ascensão e a permanência de grupos intolerantes como a KKK advêm de inúmeros fenômenos políticos, sociais e culturais e não podem ser explicados de forma simplista. Contudo, vale lembrar que pensamentos racistas ainda estão presentes na sociedade contemporânea e, uma prova disso, é o crescimento de governos de extremadireita em países europeus. Até mesmo na França, chamada berço dos direitos do homem, um candidato fascista quase se tornou presidente. Também os movimentos neonazistas, amplamente difundidos com a Internet, ganham adeptos ao redor do mundo e, até mesmo, no Brasil, tradicionalmente considerado pacífico, com os Carecas do ABC. Para Sérgio Adorno, analisando o racismo brasileiro, "a cordialidade existe desde que os negros se mantenham segregados, isolados; ou seja, desde que não reivindiquem o direito a ter direitos, pois quando o reivindicam, distintos segmentos da sociedade reagem com intolerância" (1996, p. 258).

Nos Estados Unidos, existem, inclusive, igrejas cristãs criadas para difundir o racismo e louvar líderes como Hitler. Entretanto, o dito bode expiatório desses grupos não é mais preferencialmente o judeu: negros, latinos, deficientes e muçulmanos ampliaram o leque de perseguição dos fanáticos. De acordo com Pereira:

(...) ao contrário do que pensava toda uma geração de otimistas e ingênuos, ele (o racismo) não havia sido sepultado. Permanecera, apenas, anestesiado durante um quinhão de tempo para, hoje, reaparecer com os mesmos e velhos ingredientes tradicionais condicionados pelas configurações históricas da atualidade (1996, p.258).

O fato é que a sociedade é treinada para tolerar o que deveria ser intolerável. Traços de intolerância e racismo existem até mesmo em governantes que pretendem dominar economicamente outros países, bombardeando-os com a desculpa de eliminar o mal do mundo. Não nos cabe julgar a legitimidade ou não de tais fenômenos históricos. Resta-nos, como críticos da memória coletiva, buscar explicações que contestem (ou acalmem) o nosso subjetivo presente. 


\section{Referências bibliográficas}

ADORNO, Sérgio. Violência e racismo: discriminação no acesso à justiça penal. IN: SCHWARCZ, Lilia Moritz \& QUEIROZ, Renato da Silva (orgs.). Raça e diversidade. São Paulo: Edusp, 1996.

ANDERSON, Benedict. Nação e consciência nacional. São Paulo: Ática, 1989.

BAUMAN, Zygmunt. Modernidade e Holocausto. Rio de Janeiro: Jorge Zahar, 1998.

BENJAMIN, Walter. O narrador. Considerações sobre a obra de Nikolai leskov. In: Magia e técnica, arte e política. 3.ed. São Paulo: Brasiliense, 1987.

ECO, Umberto. Definições léxicas. IN: Intolerância. Foro Internacional sobre a intolerância. Unesco, março/1997. Sorbonne. Trad. Eloá Jacobina. Rio de Janeiro: Bertrand Brasil, 20oo.

ELIADE, Mircea. História das Religiões. São Paulo: Martins Fontes, 1998.

FERRO, Marc. Cinema e História. Rio de Janeiro: Paz e Terra, 1992.

FRANCO JÚNIOR, Hilário. A Eva Barbada: ensaios de mitologia medieval. São Paulo: Edusp, 1996.

FRANKLIN, John Hope. Raça e História: ensaios selecionados (1938-1988). Rio de Janeiro: Rocco, 1999.

JUNQUEIRA, Mary Anne. Estados Unidos: a consolidação da nação. São Paulo: Contexto, 2001.

PEREIRA, João Baptista Borges. O retorno do racismo. IN: SCHWARCZ, Lilia Moritz \& QUEIROZ, Renato da Silva (orgs.). Raça e diversidade. São Paulo: Edusp, 1996.

RICCEUR, Paul. Etapa atual do pensamento sobre a intolerância. IN: Intolerância. Foro Internacional sobre a intolerância. Unesco, março/1997. Sorbonne. Trad. Eloá Jacobina. Rio de Janeiro: Bertrand Brasil, 2000.

XAVIER, Ismail. D.W. Griffith. São Paulo: Brasiliense, 1984.

Recebido em: 17/03/11

Aceito em: 01/o6/11 
LILIAN CREPALDI DE OLIVEIRA

liliancrepaldi@uol.com.br

Doutoranda em Comunicação e Semiótica pela PUC-SP, mestre em Ciências da Comunicação pela ECA-USP, bacharel em Comunicação Social (Jornalismo) pela UMESP e bacharel e licenciada em História pela USP. É professora da Faculdade Paulus de Tecnologia e Comunicação (FAPCOM-SP). Como pesquisadora, dedica-se aos temas: comunicação e cultura, identidades, movimentos sociais e jornalismo cultural. 